\title{
Chloride Penetration in mortars with replacements of rice husk Ash and nano-SiO
}

\author{
M.J. Pellegrini-Cervantes ${ }^{1,2}$, F. Almeraya-Calderon ${ }^{3}$, F.J. Baldenebro-Lopez ${ }^{2}$, \\ R.E. Nuñez Jaquez ${ }^{2}$, G. Fajardo-San-Miguel ${ }^{4}$, J.G. Chacón-Nava ${ }^{1}$, C.P. Barrios- \\ Durstewitz $^{2}$, A. Martinez-Villafañe ${ }^{1}$ \\ ${ }^{1}$ Centro de Investigación en Materiales Avanzados, Física de Materiales, Miguel de Cervantes 120, Chihuahua, \\ Chihuahua. C.P. 31109, México. \\ ${ }^{2}$ Facultad de Ingeniería Mochis, UAS - Universidad Autónoma de Sinaloa. Fuente de Poseidón y calle Ángel \\ Flores S/N, Los Mochis, Sinaloa C.P. 81223, México. \\ ${ }^{3}$ Universidad Autónoma de Nuevo León. Centro de Innovación e Investigación en Ingeniería Aeronáutica. \\ Ciudad Universitaria. San Nicolás de los Garza, Nuevo León, México \\ ${ }^{4}$ Facultad de Ingeniería Civil, UANL - Universidad Autónoma de Nuevo León \\ Av. Universidad S/N, Ciudad Universitaria. San Nicolás de los Garza, Nuevo León. C.P. 66450, México.
}

\begin{abstract}
Ashes and nanoparticles (NP) have been incorporated individually in mortars to improve its macrostructure and microstructure. However, regarding the simultaneous use of ashes and NP there are few reports addressing the study of resistance to corrosion.

It was evaluated in this work the mechanical, physical and electrochemical performance in mortars with plastic consistency according to ASTM C 1437-99, replacement of ordinary Portland cement (OPC) by rice husk ash (RHA) and nano Silica Oxide (nSO), conducting studies of mechanical resistance to simple compression, porosity, superficial absorption, rapid chloride penetration test (RCPT) and accelerated corrosion in mortars with replacements of OPC of $1.0 \%$ of $\mathrm{nSO}$ and $20.0 \%$ of RHA. According to results, the simultaneous use of $\mathrm{nSO}+\mathrm{RHA}$ has a higher performance in the properties of mortars with decreases in porosity and total charge passed of $3.9 \%$ and $75.6 \%$, and increase in compressive strength, and corrosion of $7.1 \%$ and $37.6 \%$, respectively.

Mortars of plastic consistency with replacement of OPC by RHA and nSO in simultaneous use count with higher performance in their physical, mechanical and electrochemical properties than in individual use of RHA and $\mathrm{nSO}$.
\end{abstract}

Keywords: - mortar-nanometer, total-porosity, rapid-chloride-penetration-test, accelerated-corrosion,

\section{INTRODUCTION}

Corrosion of reinforcement in mortars demerits its durability due to the damages caused by the corrosion products in the cement matrix [1,2], being that the use of steel as reinforcement leads to risks of corrosion, the pore solution of mortar can transport aggressive ions, such as chlorides, up to the reinforcement, decreasing the durability [3, 4]. In various investigations OPC has been replaced with different types of ash in order to provide durability to mortars, such as: RHA [5, 6], cane bagasse ash, fly ash, blast furnace ash, among others, improving mechanical, physical, chemical and electrochemical properties and contributing to diminish the effect of corrosion of reinforcement in various noxious environments [7]. Particularly, the RHA is a waste product of processes in industrial plants that has been used as replacement of OPC, improving properties of the matrix and contributing to environmental aspect when replacing the use of OPC [8, 9, 10]. Besides ash, different researchers have used NP as an addition or replacement of OPC in mortar mixes [11].

Currently, there is research where nSO has been used to improve various properties of mortars by the replacement of OPC $[12,13]$. Furthermore, the simultaneous use of nSO and ash presents a higher performance in the properties of mortars at early ages, resistance to corrosion and as a consequence an increased durability $[14,15,16,17,18,19]$. However, researches that combine the use of nSO and ash are scarce [12, 13, 14], in particular scientific papers related to reinforced mortars with replacements of OPC by nSO and RHA which address the issue of durability and corrosion of reinforcement [20]. Due to the replacement of OPC by RHA and $\mathrm{nSO}$ the microstructure of the cement matrix in mortar is favored being more compact, it presents improvements in the macrostructure in mechanical resistance and corrosion, being consequently more durable. 
Chloride Penetration in mortars with replacements of rice husk Ash and nano-SiO

The purpose of this research was to study the performance of physical, mechanical and electrochemical properties of mortars with replacements of OPC by $20 \%$ RHA and $1 \%$ nSO individually and simultaneously, conducting studies of porosity at open pore, resistance to simple compressive strength, resistance to chloride penetration and accelerated corrosion test with impressed voltage (ACTIV).

\subsection{Materials}

\section{EXPERIMENTAL PROCEDURE}

For the production of specimens, silica sand was used as fine aggregate with 2.68 fineness modulus, $2645 \mathrm{~kg} / \mathrm{m} 3$ mass density and 4.1\% absorption according to ASTM C 33-03 [21], OPC, commercial nSO, RHA, distilled water and superplasticizer (SP) according to ASTM C 949/C 494M-99a (22). RHA was obtained from industrial wastes from Odisha, India, subjected to a grinding process and sieved in a 325 mesh screen. Physical properties of cementitious materials are presented in Table $\mathbf{1}$ and the chemical properties of cementitious are presented in Table 2.

Table 1. Physical properties of cementitious materials

\begin{tabular}{|c|c|c|c|}
\hline PROPERTY & OPC & RHA & nSO \\
\hline Bulk density $\left(\mathrm{kg} / \mathrm{m}^{3}\right)$ & 3071 & 2251 & - \\
\hline Superficial area $\left(\mathrm{m}^{2} / \mathrm{g}\right)$ & 20.23 & 23.82 & 777.7 \\
\hline Average particle size $(\Phi \mathrm{m})$ & 27.61 & 29.88 & 0.015 \\
\hline
\end{tabular}

Table 1. Chemical components of materials

\begin{tabular}{|c|c|c|c|}
\hline OXIDE & OPC & RHA & nSO \\
\hline $\mathrm{SiO}_{2}$ & 20.046 & 84.375 & 71.451 \\
\hline $\mathrm{SO}_{3}$ & 2.589 & 0.080 & - \\
\hline $\mathrm{Fe}_{2} \mathrm{O}_{3}$ & 1.976 & 0.309 & - \\
\hline $\mathrm{Al}_{2} \mathrm{O}_{3}$ & 0.294 & 0.235 & N.D.* \\
\hline
\end{tabular}

*N.D. Not Detected

\subsection{Preparation of mixture and specimens.}

It was used in mixtures a relation water / cementitious (A / cm), Sand / Cementitious of 0.55 and 2.75, respectively, and SP until achieve a $110 \pm 5 \%$ fluidity according to ASTM C 1437-99 [23] with method of mixing process [18] according to ASTM C 305-12. The dosage of cementitious defines the nomenclature of the mixture, in $M c c-b b-a a c c, b b$ and aa are the percentages of OPC, RHA and nSO of the total of the cementitious, respectively.

\subsection{Total porosity and y resistance to compression.}

The test of resistance to simple compression was performed according to ASTM C 109 / C 109M-05 [24] and the porosity of the hardened mortar was made at open pore in vacuum saturated condition, accepted method in a satisfactory manner in various investigations of cementitious materials [25, 26]. In both assays 2.5 $\mathrm{cm}$ side cubic specimens were used and cured in distilled water for 30 to 90 days.

\subsection{Rapid chloride penetration test (RCPT)}

RCPT provides as a result the past full charge, used to classify a mortar by its permeability to chlorides. RCPT was performed according to ASTM C1202-97 [27] with the variant of the utilization of 5.0 in diameter x $4.0 \mathrm{~cm}$. in height mortar test tubes at the age of 90 days in hardened mortar.

\subsection{Accelerated corrosion test with impressed voltage.}

The performance of a mortar on assay ACTIV is in function of the physical, mechanical and electrochemical properties, being the initiation time of the first crack (TIFC) of ACTIV used to infer the resistance to corrosion [24]. The dimension of the prismatic specimens used was of 4.0x4.0x16.0 cm, $0.95 \mathrm{~cm}$ of diameter of the reinforcement, steel surface exposed to saline medium of $37.3 \mathrm{~cm}^{2}$ for 90 days age. It was used as electrolyte aqueous solution to the $5 \% \mathrm{NaCl}$ and $12.0 \pm 0.1 \mathrm{~V}$ impressed current at $25 \pm 2{ }^{\circ} \mathrm{C}$ temperature, the experimental arrangement of ACTIV is shown in Figure 1. The impressed current in ACTIV was applied until the appearance of the first crack recording the TIFC. 


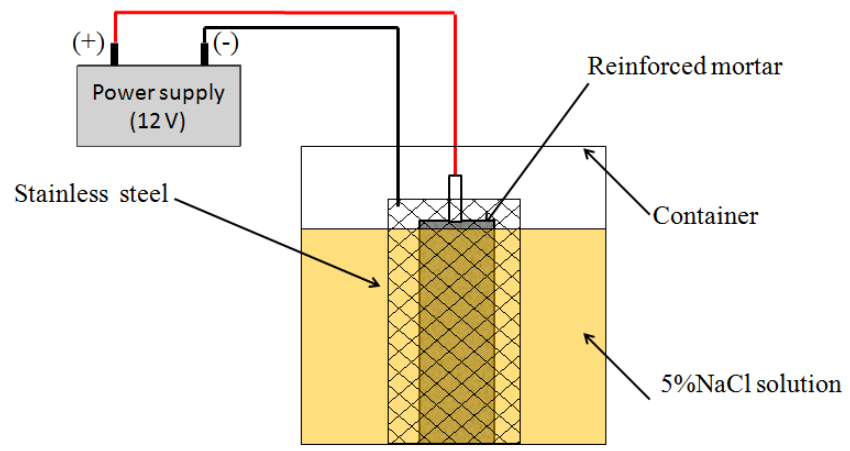

Figure 1. Experimental setup ACTIV assay.

\subsection{Materials}

\section{RESULTS AND DISCUSSIONS}

The replacement of Cement by ash and nanoparticles contributes to improve the mortar properties due to the beneficial action caused in its microstructure [4, 10]. Based on results shown in Table 2 and according to ASTM C618-99 [28], RHA is a calcined natural ash type $\mathrm{N}$ and respect to the oxide content it has that $\mathrm{SiO}_{2}+\mathrm{Fe}_{2} \mathrm{O}_{3}+\mathrm{AlO}_{3}=84.92 \%$ y $\mathrm{SO}_{3}=0.080 \%$, acceptable according to ASTM C618- 99. Cementitious properties according to their size and particle distribution, physical and chemical properties are determinant for the characteristics of the microstructure and macrostructure of mortars.

\subsection{Mixes and morphology of hardened mortar}

The adequate dispersion of ashes and NP in the matrix of mortar is needed to achieve properties with superior performances to those obtained with the simple use of cement, the use of ashes and NP demand more quantity of water in the mixing, being accepted the use of SP to achieve comparable fluidity between mixtures $[29,30]$. In mixtures made in the present work, the amount of SP respect to the weight of the cementitious ranged from 0.9 to $2.8 \%$, achieving the microstructures of hardened mortars shown in Figure 2 . The replacement of the OPC by RHA and nSO in the mortars mixture produced morphologies of the cement matrix more compact in M79-20-1 than in M100-0-0, M99-0-1 and M80-20-0, promoting benefits in physical, mechanical and electrochemical properties.

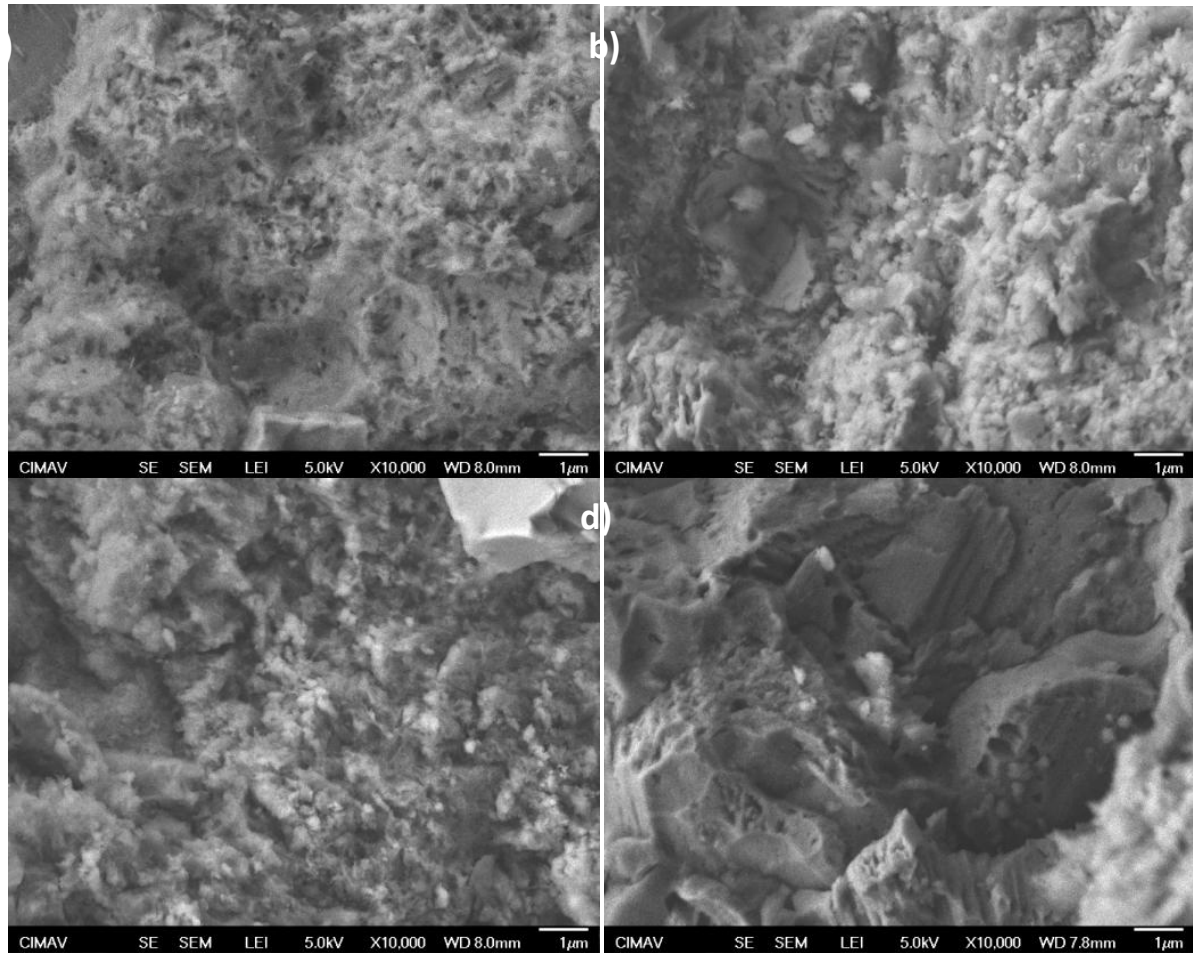

Figure 2. SEM hardened mortars 90 days aged,

a) M100-0-0 b) M99-0-1 c) M80-20-0 d) M79-20-1 
Chloride Penetration in mortars with replacements of rice husk Ash and nano-SiO

\subsection{Rapid chloride penetration test.}

The RCPT realized according to ASTM C1202-97 provides as a result the total charge passed through the mortar mass, used to classify the mortars according to its chloride permeability. With the simultaneous use of other types of ash, some authors have achieved increases in the performance of chloride penetration of up to 90\% [28]. In mortars made, the individual replacement of OPC by RHA and nSO increased the performance to the chloride penetration decreasing 74.0 the total charge passed and $1.1 \%$ of the reference respectively; while in the simultaneous use of RHA and nSO the charge passed decreased $75.6 \%$. There is a marked difference in the benefit obtained with the individual use of RHA and nSO, RHA reduces the charge passed to a $26.0 \%$ of the reference well below nSO in individual use. The use of SP in the manufacture of mortars limited the expected performance with the simultaneous use of RHA and nSO increasing the porosity of the cement matrix to higher content of SP, however a higher performance with the simultaneous use of RHA and nSO was obtained. It is of great relevance, in the use of mortars, its physical and mechanical behavior besides of the electrochemical issue, since in various productive sectors, such as the construction sector, they have an important role.

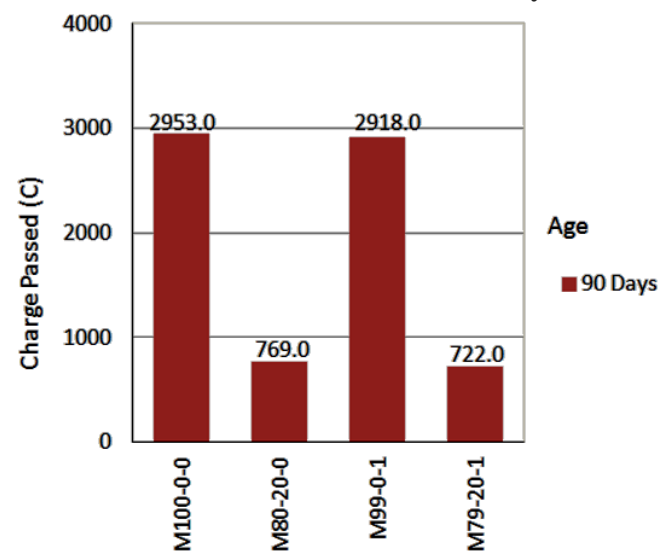

Figure 3. Total charge passed of hardened mortars according to RCPT

\subsection{Total porosity and compressive strenght.}

Total porosity of mortars decreases with OPC replacements by RHA [Error! Bookmark not

defined.]. In mortars made, total porosity is shown in Figure 4, in single replacement of OPC by RHA the porosity decreased in performance, increasing 5.1 and $3.9 \%$ for 30 and 90 days respectively, which is attributed to the use of SP. However, the replacement of OPC by nSO, individually or simultaneously, favored the performance of the porosity, featuring within 30 days a decrease of $0.8 \%$ porosity in M99-0-1. At 90 days of age, the simultaneous replacement of OPC by RHA and nSO was more effective, presenting the minimum porosity of the total of the mixtures in M79-20-1 with a decrease in porosity of 3.9\% of the reference. The replacement of OPC by RHA + nSO presented favorable performances at ages older than 30 days, the use of SP increased the porosity of the mixture and delayed the benefit obtained by the replacement of OPC by RHA and nSO. Several investigations $[3,4,9,10]$ demonstrate an acceptable increase in the performance of the physical and mechanical properties of mortars by performing replacements of OPC by RHA or nSO.

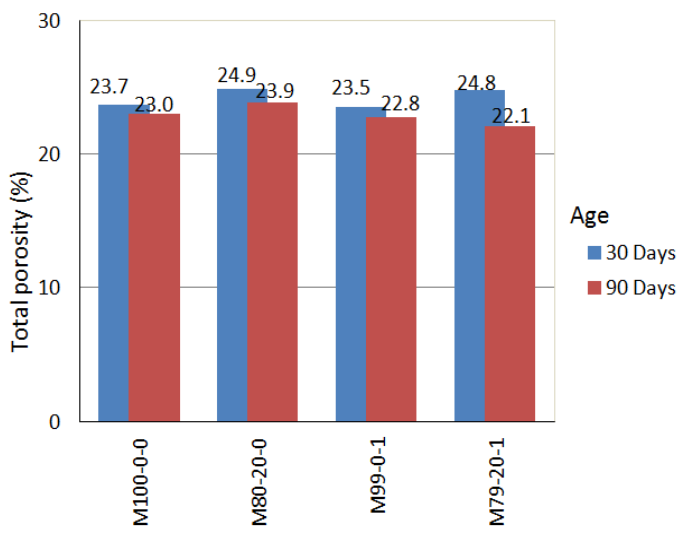

Figure 4. Total porosity of hardened mortars

On the other hand, in mortars made, the simple compressive strength is shown in Figure 5. In all cases the performance increased with the presence of RHA or nSO to age 30 and 90 days, taking up to 7.2 and $7.1 \%$ at 
30 and 90 days respectively in replacement of OPC by RHA + nSO. Whereby, regarding the compression strength in mortars with plastic consistency with the replacement of OPC by RHA + nSO higher performances are obtained than in the case of individual replacement. Concerning the durability of reinforced mortars, the physical and mechanical properties are of great importance, however, the resistance to corrosion plays an essential role.

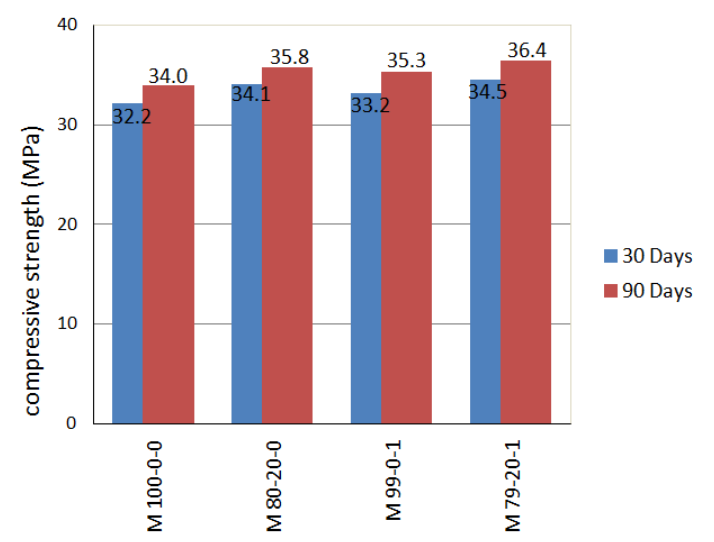

Figure 5. compressive strenght of hardened mortar.

\subsection{Accelerated corrosion test with impressed voltage.}

ACTIV provides as a result the TIFC which combines the interaction of mechanical resistance and the mechanical resistance of a hardened mortar due to the effects produced by the corrosion of the reinforced steel [24]. Of the mortars made, TIFC results are presented in Figure 6 and the state of specimens after the application of ACTIV in Figure 7. In all replacement cases of OPC a more favorable performance was obtained than in the reference. For OPC replacement by RHA a 32.3\% TIFC was increased, with nSO the increase was $30.1 \%$ and with RHA + nSO the increase was the highest with $37.6 \%$, starting from the reference. The order of the performance shown in ACTIV corresponds to the one obtained on the mechanical resistance and is very similar to that presented in porosities. According to results, the best performance of the mortars in ACTIV is had with the replacement of OPC by RHA + NOS followed by individual use of RHA.

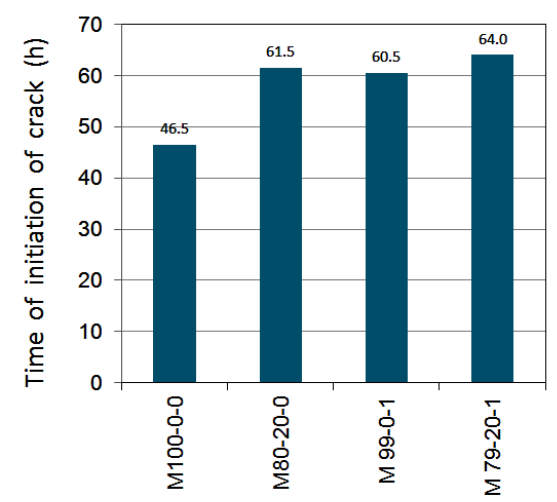

Figure 6. TIFC in assay of Accelerated corrosion test with impressed voltage.
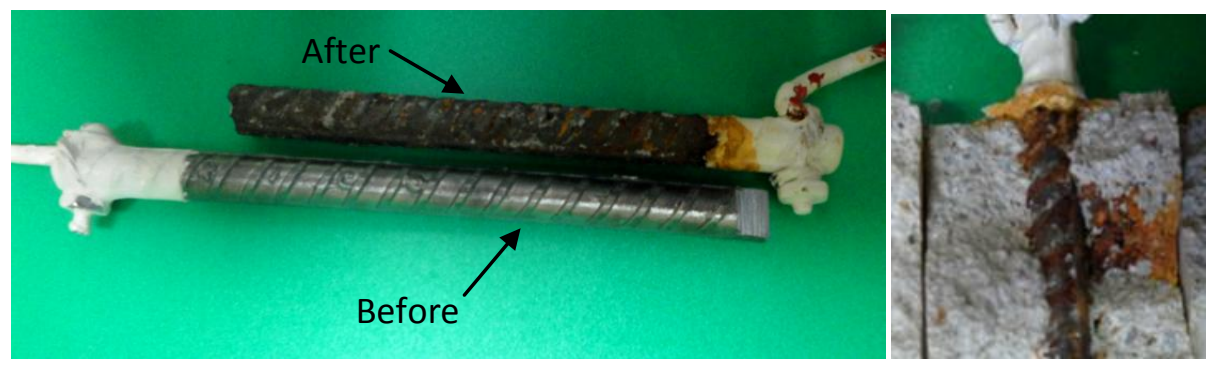

Figura 7. Reinforcing Steel after ACTIV.

\section{CONCLUSION}

According to results, a demerit is presented on the properties of mortars with plastic consistency with replacement of OPC by RHA and nSO due to the use of SP, by counteracting the part of the benefits in Chloride 
Chloride Penetration in mortars with replacements of rice husk Ash and nano-SiO

Penetration provided by the use of RHA and nSO. The simultaneous use of RHA and nSO as replacement of OPC presents a higher performance than its single use in physical, mechanical, chloride penetration and resistance to corrosion due to the synergistic effect of ash and NP.

\section{ACKNOWLEDGEMENTS}

The authors express their gratitude to Centro de Investigación en Materiales Avanzados (CIMAV), Universidad Autónoma de Sinaloa (UAS), Universidad Autónoma de Nuevo León (UANL) and Grupo Cementos Chihuahua (GCC).

\section{REFERENCES}

[1] L. Hanzic and L. Ilic, Relationship between liquid sorptivity and capillarity in concrete, Cement and Concrete Research, 33 (9), 2003, 1385-1388.

[2] R. Kumar and B. Bhattacharjee, Study on some factors affecting the results in the use of MIP method in concrete research, Cement and Concrete Research, 33 (3), 2003, 417-424.

[3] R. Muñoz-Ledo y J. Uruchurtu-Chavarín, Caracterización de la agresividad atmosférica sobre los materiales metálicos estructurales en la zona metropolitana de la ciudad de México. Revista Internacional de Contaminación Ambiental UNAM. 18(1), 2002, 27-32

[4] J. A. Chávez-Machado y H. Buendía-Ríos, Perfiles de penetración de cloruro en estado iónico en concretos del rango A/C 0.45 a 0.65 . Rev. Inst. investig. Fac. minas metal cienc. geogr. 6(12), 2003, 3643.

[5] B. Chatveeraa and P. Lertwattanaruk, Durability of conventional concretes containing black rice husk ash, Journal of Environmental Management, 92 (1), 2011, 59-66.

[6] A. A. Ramezanianpour, M. Mahdi khani and G. Ahmadibeni, The effect of rice husk ash on mechanical properties and durability of sustainable concretes, International Journal of Civil Engineerng, 7(2), 2009, 83-91.

[7] V. Saraswathy and H.W. Song, Corrosion performance of rice husk ash blended concrete, Construction and Building Materials, 21(8), 2007, 1779-1784.

[8] P. Chindaprasirta , S. Homwuttiwongb and C. Jaturapitakkulb, Strength and water permeability of concrete containing palm oil fuel ash and rice husk-bark ash, Construction and Building Materials, 21(7), 2007, 1492-1499.

[9] P.K. Mehta. Rice husk ash - a unique supplementary cementing material, In: Advances in concrete technology, 2nd ed. CANMET, 1994, 419-44.

[10] V.T.A. Van, C. Rößler, D.D. Bui and H.M. Ludwig, Mesoporous structure and pozzolanic reactivity of rice husk ash in cementitious system, Construction and Building Materials, 43, 2013, 208-216.

[11] F. Pacheco Torgal and S. Jalali, Nanotechnology: Advantages and drawbacks in the field of construction and building materials, Construction and Building Materials, 25(2), 2011, 582-590.

[12] A. Nazari and S. Riahi, The effects of $\mathrm{SiO} 2$ nanoparticles on physical and mechanical properties of high strength compacting concrete, Composites: Part B, 42(3), 2011, 570-578.

[13] A. Naji Givi, S. A. Rashid, F. N. A. Aziz and M. A. Mohd Salleh, The effects of lime solution on the properties of $\mathrm{SiO}_{2}$ nanoparticles binary blended concrete, Composites: Part B, 42(3), 2011, 562-569.

[14] G. Li, Properties of high-volume fly ash concrete incorporating nano- $\mathrm{SiO}_{2}$, Cement and Concrete Research, 34(6), 2004, 1043-1049.

[15] T. Ji, Preliminary study on the water permeability and microstructure of concrete incorporating nano$\mathrm{SiO}_{2}$, Cement and Concrete Research, 35(10), 2005, 1943-1947.

[16] Y. Qing, Z. Zenan, K. Deyu and C. Rongshen, Influence of nano-SiO2 addition on properties of hardened cement paste as compared with silica fume, Construction and Building Materials, 21(3), 2007, 539-545.

[17] D.F. Lin, K.L. Lin, W.C. Chang, H.L. Luo and M.Q. Cai, Improvements of nano-SiO ${ }_{2}$ on sludge/fly ash mortar, Waste Management, 28(6), 2008, 1081-1087.

[18] K.L. Lin, W.C. Chang, D.F. Lin, H.L. Luo and M.C. Tsai, Effects of nano-SiO2 and different ash particle sizes on sludge ash-cement mortar, Journal of Environmental Management, 88(4), 2008, 708-714.

[19] H.L. Luo, W.T. Kuo and D.F. Lin, The Application of Waterworks Sludge Ash to Stabilize the Volume of Cement Paste, Water science and technology, 42(3), 2011, 570-578.

[20] M.J. Pellegrini, F. Almeraya and A. Martinez, Corrosion Resistance, Porosity and Strength of Blended Portland Cement Mortar Containing Rice Husk Ash And Nano-SiO ${ }_{2}$, International Journal of Electrochemical Science, 8 , 2013, 10697-10710.

[21] ASTM C33-03, Standard Specification for Concrete Aggregates, Book of standards, vol. 04.02 (2003).

[22] ASTM C 494/C 494M - 05a, Standard Specification for Chemical Admixtures for Concrete, Book of standards, vol. 04.02, 2005.

[23] ASTM C 1437-99, Standard Test Method for Flow of Hydraulic Cement Mortar, vol. 04.01, 1999. 
[24] ASTM C 109/C 109M - 05, Standard Test Method for Compressive Strength of Hydraulic Cement Mortars (Using 2-in. or [50-mm] Cube Specimens), vol. 04.01, 2005.

[25] S. Rukzon, P. Chindaprasirt and R. Mahachai, Effect of grinding on chemical and physical properties of rice husk ash, International Journal of Minerals, Metallurgy and Materials, 16(2), 2009, 242-247.

[26] P. Chindaprasirt and S. Rukzon, Strength, porosity and corrosion resistance of ternary blend Portland cement, rice husk ash and fly ash mortar, Construction and Building Materials, 22(8), 2008, 1601-1606.

[27] ASTM C 1202-97, Standard Test Method for Electrical Indication of Concrete's Ability to Resist Chloride Ion Penetration1, vol. 04.01, 1997.

[28] ASTM C 618 - 99, Standard Specification for Coal Fly Ash and Raw or Calcined Natural Pozzolan for Use as a Mineral Admixture in Concrete, vol. 04.02, 1999.

[29] P.K. Metha. The chemistry and technology of cement made from rice husk ash, In: Proceeding of work shop on rice husk ash cement, 1979, 113-22.

[30] P. Chindaprasirt, S. Rukzon and V. Sirivivatnanon, Resistance to chloride penetration of blended Portland cement mortar containing palm oil fuel ash, rice husk ash and fly ash, Construction and Building Materials, 22(5), 2008, 932-938. 